\title{
6. Comparison, Individualism and 'Interactionalism' in the Work of Donald F. Tuzin
}

\author{
Don Gardner
}

\section{Introduction}

Don Tuzin left a magnificent corpus of work on the Ilahita Arapesh, one that presents a compelling analysis of two remarkable transitions in the history of a people. His work is also striking because of the sheer range of issues on which he focused his fine analytical eye; his work might focus on the emotions, dispositions and moral conflicts of particular persons or categories thereof (specific elders, initiands, or Christians, men, women) as readily as on the structural or historically contingent circumstances within which agents must act, and which tend to produce grand historical transformations. There are also significant essays that complement both these analytical poles with a consideration of apparently general human susceptibilities to certain sorts of sensory experience and their relevance to religious life. ${ }^{1}$ Finally, Tuzin was given to posing questions about the relevance of this sort of ethnographic analysis, of this sort of society, to broader comparative and theoretical matters in the social sciences. He usually did so in the course of an analysis of some aspect of Ilahita's social life, but sometimes he considered such questions specifically and explicitly; when he did so, he was liable to proclaim his allegiance to 'methodological individualism'. Such statements of position have struck even some of his closest admirers as dated or doctrinaire relative to the discipline's orthodox orientation and given the actual breadth of his analytical vision.

\footnotetext{
1 Thus, the religious imaginings of Ilahita's prophet, Samuel (a 'rather extraordinary individual' [Tuzin 1989:187]), and the political significance of the contingencies of birth order in a given family (Tuzin 1991) are no less a part of the village's history than its extraordinarily involuted dual organisation; and the tenderness that marked intra-familial relations as well as the moral equivocation - in the context of the burden that the Tambaran's productive demands placed upon women - these induced in senior men (Tuzin 1982) were as integral to Ilahita's political dynamics (Tuzin 1974) as was the competition between exchange partners (Tuzin 1976). On a different but wholly complementary tack, Tuzin also considered the work of pre-cultural experiences of certain sounds (1984), sights (2002) and smells (2006) in the construction of specifically Ilahitan cultural forms, which were thereby identified as cognate with specific forms found elsewhere. Similarly, certain Ilahita experiences, and the institutions that they thematise, bespeak the psycho-social qualities of human relationships as such, and, therefore, the comparability of culturally prepotent institutions from widely dispersed settings (Tuzin 2001).
} 
I will here consider his methodological commitments in the light, first, of his analysis of Ilahita culture and history (which I will suggest changed slightly over time) and, second, in relation to what we should make of this doctrine today and its bearing on our assessment of the work Don left.

I shall take it as uncontroversial that Tuzin saw his four books and numerous articles as dealing with interlinked dimensions of his project to portray the history of Ilahita and the lives of Ilahitans. I shall also take it for granted that Tuzin saw his analytical practice and his theoretical or meta-theoretical orientations as, at the very least, mutually consistent. Accordingly, I will probe Tuzin's methodological commitment - avowed in his first and his last books - to the principles of Popperian methodological individualism (hereinafter MI), in relation to the consistency of his analytical vision. I believe it was his sense of the complexity of the total human person in a definite historical setting, rather than any methodological primacy of 'the individual' as such, that drove and rationalises his analytical work. I will try to suggest that his strongest convictions concerned the depth of the connections at work in what he termed the culture-society-individual nexus and, therefore, the interest and legitimacy of a very broad range of questions that anthropology might pose of human life, in general or in particular. Yet it was important to him that his views be both morally and theoretically defensible, which is what drew him to Popperian MI, with its twin emphasis on science and liberal values.

Any discussion of MI today has to take account of more recent refinements in the discussion of the knot of issues that it involves. The Popperian terms in which Don made his methodological claims implicate some daunting conceptual and metaphysical issues; they also rather too easily evoke moral-political sensibilities associated with terms such as 'choice', 'reduction' and 'determinism'. The sort of ecumenical project that Tuzin's corpus represents can now be conceived in ways that he himself did not consider, and which have the virtue of avoiding certain conceptual difficulties while-in principle, anyway-not provoking anyone to mount the theoretical barricades. In short, recent considerations of the ontology of social states and processes suggest that some clarity on the vexed issues that Don felt the need to address can be achieved. I will introduce one effort to make a place for both traditional holist and traditional individualist intuitions: Philip Pettit's is one example of an attempt to differentiate questions of methodology and ontology in a way that can connect with the empirical practices of social scientists while isolating those moral-political convictions to their proper domain. With the waning of the hegemony of deductive models of explanation, and a more nuanced consideration of the ontology of social life (the sorts of dependencies it involves), old accusations of 'reductionism' lose their sting; once we make the right sort of conceptual space for psychological 
and the sociological questions, the narrowness of the opposition between 'the individual' and 'society' — which has exercised more influence than any other intellectual construct since Durkheim-becomes apparent.

\section{A Complex Science}

The historical and social sciences have always been concerned with the entire range of features relevant to human life: with persons, nations, and states, with personal situations and cultural specificities, and with the idiosyncratic and the utterly general characteristics of human sociality across time and space. Tuzin's work as a whole evinces a commitment to the idea that a similarly wide range of factors, of different degrees of generality, is relevant to the comprehensive, single-case study he undertook. This is for the most part implicit in his different books and articles on Ilahita, but it is sometimes stated plainly, as when in 'Miraculous Voices' he indicates his debt to a vision:

[One] advocated in various contexts by, among others, Freeman (1983), La Barre (1980), and Spiro (1978). Skeptical of the deterministic cant of much social-science discourse these scholars hold that human behavior is constitutive of a cultural, psychological, and biological wholeness; that human experience, in its immediacy, is profoundly oblivious of the internal partitions that gerrymandering theorists impose on it; and that the idea of the 'psychic unity' of our species should be treated neither as an empty slogan nor as a brief for the judicious neglect of biological factors in the study of culture, but as a challenge to engage the unsolved problems of the human condition in its most universal expressions. Both humane and humanistic, theirs is an anthropology of great moral and scientific importance. (Tuzin 1984:580)

An anthropology 'both humane and humanistic... of great moral and scientific importance' seems to summarise aptly the deep ambition thematising Tuzin's vision. He later explains that such an anthropology - one principled enough to follow an empirical problem wherever it might lead - would have to involve an 'interactionalist' paradigm, in which information from disciplines concerned with different aspects of 'the human condition' are brought together (Tuzin 1984:589). Here, and elsewhere, it is clear that Tuzin differs from those who see the human condition as defined by some key feature; his outlook on the human condition is sensitive to many local and universal factors, which is why its study must depend upon the synthesis produced by research perspectives in interaction. It might seem, though, that this rather pointedly raises doubts about Tuzin's uncompromising insistence on Popperian MI. 
I will begin what I intend to be a sympathetic reading of Tuzin's position by setting out some social-science commonplaces concerning persons and the societies that encompass them. Doing so will help my case, which suggests that we now (perhaps, with the waning of logical positivism, and its hostility to metaphysical notions) have better resources for characterising the complexities that prompted the old divisions than formerly.

If we consider in a Searlean manner (Searle 1995, 2010) the enormously heterogeneous range of states that a human being might be in (being pregnant or undernourished, for example, contrasts in important ways with being the local bank manager, under indictment for a crime or in debt to your maternal kin), we can see how they depend upon rather different sorts of worldly conditions. Similarly, if one contemplates the range of events or processes a person might be engaged in (eating a grape versus blessing clan sacra or studying for a driving test) or undergoing (fighting a fever versus undergoing initiation or defending a thesis) then coordinate differences become obvious. Again, if one thinks about the state, event and process terms that could be predicated of the last person left on Earth, it seems clear that some would and some would not have a use (being injured or afraid or near the beach versus under arrest or close to becoming the vice-chancellor or a ranking elder). And under that terrible condition, the suite of values, reasons and ambitions (to name just one species of motivation) that a person might have and act upon would be dramatically transformed (in logic, if not-given the historicity of human being - in psychological fact). What these considerations seem to show is not just that many of our most definitive characteristics are relational (which is true of many of the non-social predicates applying to individuals), but that the relations involve persons and their relations with other persons and institutions. (It is worth mentioning that this is also true of the social properties of physical objects; what makes a suit a police uniform, for example, has nothing to do with the intrinsic properties of the material from which it is made. This is even more clearly the case with money.)

Less dramatically, but no less clearly, while any one of us was born at the same moment as legions of other mammals (think of all those rodents), and in the same part of the world as some of them, we acquired immediately a set of identities (for they are usually packaged together) that has no counterpart to the events and conditions we might use to individuate members of those other species; we are identified relationally (by our parents and their families, our clan, our initiation class or nation-state, our legal status, and so on), even while we cannot identify with those identities. And the significance - constitutive and causalof those identities, not only to what I am at that point in time, but also to the sort of being I can become, is obvious once one takes thought. The facticity of these features of ourselves is shown, among other things, by the impossibility 
of discounting their relevance to us, whether or not we identify with particular identities (pace claims about the 'performative' nature of social identities). Repudiating those identities, which in any case is possible only later in life, if at all, is no less testimony to their facticity than embracing them with pride. And if one thinks about the institutionalised settings of much of contemporary life (in which one may need to be concerned with - among many other thingswhether one is or is not a citizen of the state, a registered resident of a town, an enrolled student or voter, a discharged bankrupt, a licensed driver or dog-owner, a member of the union or the gym, the legal owner of what one is consuming or using, the bearer of legal tender or counterfeit notes, or even an authorised passenger on the train), then it can seem that a great many of the things we care about involve states, events and processes that have no counterpart in the sad life of the last person on Earth. Finally, if we scrutinise the minutiae of our interactions with others, we see other significant factors - Goffmannian, we might call them - that have complex dependencies upon conventions, rules and practices that also enjoy a facticity with respect to ourselves, yet inflect our own actual and potential experiences, by defining the interpersonal setting in which we each find ourselves, and, hence, the sense of self we can sustain. Particular individuals are rarely in the position to control the definition of a social setting or the exact quality of its interactions and their outcomes.

If we change our focus now and consider somewhat broader states of affairs and processes, it seems we can make connected distinctions: indexes of economic inequality are higher now in the West than a few years ago, as are levels of carbon dioxide in the atmosphere; the world is, apparently, currently undergoing a change in climate, but it is also undergoing an economic crisis; the universe is expanding, but so are average household debt and unemployment. Corporations, classes and clans are subject to the vicissitudes of worldly happenings no less than moons, mountains and molehills. Nation-states and Melpa clans go into debt, declare war and join organisations of one sort or another. Connected with these and other events and processes, values, beliefs and desires undergo epidemiological processes that leave individuals and collectivities changed, sometimes decisively.

Questions - essentially ethnographic questions - about what is going on, and why, can arise about any of the features of social life indicated above; accordingly, an alternative way of making the point here would be to follow Geertz's (1973:7-9) discussion of his frequently cited 'note in a bottle', which he took to indicate the range and heterogeneity of the information relevant to the 'thickening' of the ethnographic story of the Moroccan trader's misadventures (including Cohen's history and personal characteristics, North African Jewish customs, Berber social organisation, mezrag pacts between Sheiks and traders, and French colonial history). We should also keep our eyes open to what might 
be thought of as the complement to Geertz's point, which is that we could invoke Cohen's particular circumstances to explain why, when the French were in charge and safely ensconced in their forts, the mezrag pact was still relevant to social events. If, generalising from these particularities, we think through how the different questions requiring ethnographic answers interconnect, then we can see (along with thinkers as different as Durkheim, Weber and Wittgenstein) how ethnography's significance outruns its role in providing purely local understandings. We account, for example, for a woman's self-sacrifice by reference to her determination to save her group's reputation, which she could not achieve in any other way, and to the value of the honour of one's natal group to someone produced by that way of life, which is sometimes sufficient to trump the value of life itself. And if someone contemplating the woman's actions cannot see how such values can play so central a role in anyone's life, then more exposure to the thick descriptions that good ethnography provides is all we can recommend. Similarly, someone who cannot see how anyone could labour fiendishly to amass valuables to give to a rival, rather than enjoy them himself, is suffering a very particular blindness. As Geertz always stressed, the questions ethnography addresses in small settings are not thereby small questions, andas he also stressed-such an interlocutor's failure to comprehend is most importantly in self-understanding.

What has been said so far underlines the complex dependencies that enmesh particular lives and their cultural contexts (and while I have invoked Geertz to help make the point, I could just as easily have cited Sahlins' work on historical change and continuity in Oceania). Ethnographically, descriptions need to be thick and omnidirectional if they are to play a role in answering questions about events on different scales. Social-science theorists' ambitions tend, however, to outrun intuitions concerning interconnections between the various orders of facts that ethnography and historiography describe. Theorists of social life working under very different conceptions of what adequacy amounts to have agreed that some verdict must be reached about the fundamental direction in which genuinely explanatory dependencies run.

Tuzin also felt the need to enter the lists on these matters, and he did so with some passion. I will argue that more recent reflection on them indicates that different aspects of Tuzin's project need to be evaluated separately -in particular, his interests in an interactionalist approach to social life and his concern with comparison are not particularly well defended by his MI; indeed, they are more defensible once his Popper-inspired methodological dicta are set aside. 
6. Comparison, Individualism and 'Interactionalism' in the Work of Donald F. Tuzin

\section{The Account of Ilahita and Methodological Individualism}

\section{The Earlier Works}

Tuzin gives his only reasonably extended account of what it means to adopt MI in the course of the introductory chapter of his first book, The Ilahita Arapesh, where he also defends what might seem to be 'the arrant parochiality' of asking what made the village become so extraordinarily large and what enabled it to maintain its unity (1976:xxi).

In this first volume, the focus is the complex dual organisation of Ilahita village, which Tuzin sees as a structural accommodation to the difficultiesin particular, the population pressures - caused by refugees displaced by the Abelam expansion (see Roscoe, this volume). The book argues that the elaborate organisation that resulted is traceable to, and is maintained by, the cumulative effects of individual actions of interconnected, culturally similar agents responding to the circumstances they face. The complex, crosscutting structures of dual classes are detailed and their effects in binding together the various segments of this large population demonstrated by the rich ethnographic material Tuzin commanded and used expertly. He left for his second volume almost all ritual aspects of these structures, but their importance was a constant background theme in the first.

Tuzin presents a historical picture in which a local system, made up of a social order — with its own 'inherent dynamic' that 'tends to homeostasis' is integrated into a more or less constant environmental setting to produce something approximating equilibrium. Wider historical forces necessitated adjustments in the narrower social process since they presented problems that the prior homeostatic system was not required to face (Tuzin 1976:xxii-xxiv). The most pressing of these problems relates to Ilahita's adaptive increase in size, which nullified the possibility of 'remedial changes of residence' that the previously more fluid settlement patterns permitted; 'the various problems chronically infecting relations of proximity, kinship and political rivalry' (which his own ethnographic data document) were not only harder to resolve in the new Ilahita, they increased (Tuzin 1976:xxiv). Accordingly, the need to 'manage' the difficulties and resolve the tensions was great; the response was 'the elaboration of regulatory, integrative mechanisms'. Of particular significance was the evolution of the intricate web of complementary identities that constituted Ilahita's highly complex dual organisation, which was '[r]eplete with cohesive functions' (Tuzin 1976:xxiv-v). 
It is at this point - where, so to speak, management needs, responses and functions have been rather equivocally invoked - that Tuzin sees 'yet another processual mode' as being implied, one wherein the components of the dual organisation are created and re-created 'from the lower levels' of quotidian existence in the expanded community. The dual organisation's many components depend upon this input from 'mundane behavioral spheres', in their initial development and for their reproduction; and, it is important to stress, his account 'predicates the rarefied dual structures on the motivations of individuals operating within a changing socio-cultural setting' (Tuzin 1976:xxv). So the 'management' he speaks of is not, or not only, to be interpreted as a metaphor for the feedback connections within the system, but as something the need for which confronts particular people through the problems some of their interpersonal relations now represent. As a result of the expansionary pressures of southern groups, Arapesh people faced difficulties in their lives - the arrival of refugees, the threat of raids, difficulties with subsistence, and so on - to which they had to respond. Their responses, grounded in their pre-existing values and beliefs, were what, over time, crystallised into the complex structures that had mystified regional specialists such as Anthony Forge, who advised Tuzin to conduct research in Ilahita.

Notice that Tuzin has used both psychological motivations and social functions in explaining Ilahita's adaptive responses; the ancestors of contemporary Ilahitans responded to novel demands on their existing relationships with one another by using cultural items to hand (conspicuous among which was the regionally characteristic practice of defining social categories in terms of a dual organisation [Tuzin 1976:xxv]) to deal with the new social setting. In so doing, new conceptions of relatedness and shared identity emerged that proved adequate to the new social setting. It is at this point - early in setting out his thesis about Ilahita's growth - that Tuzin refers to Lévi-Strauss for the first time. He does so only to stress that he will later argue against the structuralist accounts of dual organisation, foreshadowing that his views and those of Lévi-Strauss 'embody fundamentally distinct philosophical orientations, intellectual stances whose relevance extends far beyond theories of dualism per se to demarcate alternative perspectives on culture, society and the individual' (Tuzin 1976:xxv). And it is here, having referred to the three elements whose relationships constitute the 'central problem of anthropology' (Tuzin 1976:338), that he tells us that his analysis of Ilahita dual organisation 'will be guided in large measure by the principle of methodological individualism' (p. xxv) - a notion he then discusses in rather definite terms.

The most important point - 'the heart of the principle' (Tuzin 1976:xxvii) - is that social structure arises out of what Tuzin, quoting Popper, characterises as the "indirect, the unintended and often unwanted by-products" of decisions 
and actions', which agents take 'according to the logic of their situation'; actions taken by individuals are represented in MI as the source of both social stasis and social change (p. xxvi). The rationale, he seems to suggest, is importantly given by its negation, methodological collectivism or holism, which, 'in its pure form', portrays individuals as 'a reifying fiction, a walking bundle of social rules, statuses, values and similar abstractions' (Tuzin 1976:xxvi). The individuals invoked by MI are not particular historical persons, but anonymous agents, each of whom is also 'presumed to be a competent member of a society, steeped in [its] norms and values', not the mythical pre-social individual postulated by reductionist nineteenth-century theorists (Tuzin 1976:xxvii). Nevertheless, the norms and values possessed by those competent members of society themselves 'originate in, and are actualized through, the interactions of individuals, and, therefore, cannot logically precede these interactions' (Tuzin 1976:xxvii). Tuzin later makes the point that the individuals invoked by MI might indeed possess 'holistic concepts', but these are to be treated as data by the analyst (1976:335) - as part of what is to be explained, rather than what provides explanatory resources. Although MI holds that the social structural effects of actions are unintended and unforeseen by individuals, even when they are consciously planning to affect social structure, it does not exclude 'rationality or premeditation' (Tuzin 1976:xxvii). On the contrary, our actions are indeed 'governed by relatively immediate considerations... we apply to any given situation a calculus, not only of social prescriptions and values, but also of personal strategies, psychological proclivities and other factors which are, in principle, determinable' (Tuzin 1976:xxviii). Once these individual-level processes have been analytically identified, it is possible to link them to societal consequences. Here Tuzin makes a reference to Adam Smith and his principle of individual expediency as the basis for economic institutions (although he does not explicitly invoke the 'invisible hand').

The strength of MI, Tuzin continues, is that it sets on centrestage the individual - an 'empirically isolable unit of observation' - that is also a 'conceptual link' between the psychological and the sociological sciences and 'our guide through many of man's domains' (Tuzin 1976:xxiv). Accordingly, MI expects (indeed, it 'celebrates') variation between individuals and sees 'change as an inherent property of human groups' (Tuzin 1976:xxix, emphasis in original). In the context of his account of Ilahita and its increase in size and structural complexity, this methodological orientation entails the study of the factors impacting upon the population of individuals and their interactions, given both what they share culturally - the concepts, norms and valuesand how they differ (with respect to their situations and inclinations). It also involves tracking how, under historically new, challenging conditions, what he calls the 'actional field' becomes constituted by this configuration of responses. More generally, Tuzin continues, 'by deducing the "unintended" repercussions 
of this actional field' (emphasis added), we come to understand what Watkins called the 'organic-like' feature of social systems, wherein a collection of people whose actions affect one another 'mutually adjust themselves to the situations created by the others in a way which, without direction from above, conduces to the equilibrium or preservation or development of the system' (1976:xxixxxx, quoting Watkins 1957:114). Tuzin then takes Watkins' final formulation for his own purposes: 'In the present study, the system whose equilibrium, preservation and development we are seeking to explain is the social entity of Ilahita village' (1976:xxx).

If Tuzin is emphatic about MI's virtues, so too is his case for viewing LéviStraussian commitments as empirically inadequate to a comprehensive anthropology: structuralism indulges itself with 'other concerns, such as the imponderables of metaphysics and unreconstructable history...the elusive objects of pleasurable speculation' (Tuzin 1976:338-9). Yet the book is overwhelmingly concerned with a complex and convincing empirical analysis of Ilahita's social organisation; rereading it and the second volume (Tuzin 1980), and reading back over some of his earlier papers, makes it clear how theoretically wide ranging Tuzin was; and, despite occasional polemical flourishes and firm statements, he rarely seems doctrinaire. I believe that even at this early stage, the real attraction of MI for Tuzin was that it provided the sort of meta-theoretical orientation that could rationalise the distaste he felt for 'gerrymandering' theory. It also provided a context for a perspective on cultural order as 'processual' in nature and in complex two-way dependencies with the actions taken by individuals and, hence, with their psycho-dynamic characteristics; all this he took to be demanded by the unusual empirical situation Ilahita presented. His works repeatedly return to the 'fit' between processes of cultural reproduction and the behaviours generated by the existential conditions of individuals' lives. Strikingly, he insists that the scepticism, deception and playfulness that life can induce, as well as the moral tensions generated by routine interaction, are as necessary to particular institutional processes as are the cultural norms and values that channel them. All of these particular factors and their interactions are discussed in terms that are highly sensitive to the general historical conditions of cultural contexts and persons. Such a concern with the mutual conditioning of factors usually thought of as at different levels, and the sensitivity of historical outcomes to the subtlety of that conditioning, evokes something like a Weberian perspective on 'the relationship between culture, society and the individual', as I shall underline later. Be that as it may, Tuzin insisted from his earliest works that the conspicuous elaboration of ritual and social form in Ilahita is to be grasped as a process, initiated and then sustained by historical circumstances, not simply a product of the passage of time or an abstract endogenous force: 'the elaboration and maintenance of [the dual] organization is traceable to the cumulative effects of individual actions 
conditioned by the press of broadly shared circumstances amid the constraints of equally shared cultural understandings' (Tuzin 1980:335, emphasis added). I submit that the historical contingency of social processes became analytically more central over the period between his first and his last books.

\section{Social Complexity in the Making}

With his later work, Social Complexity in the Making (2001), Tuzin sought to reposition his ethnographic findings from Ilahita in relation 'both to general issues of social evolution and, more specifically, to the major transitions undergone by Ilahita that have also occurred in many other times and places in world history' (p. xii). He begins, though, with another critique of the discipline's usual orientations. The overreaction of anthropology to nineteenthcentury evolutionism led to the exclusion of history, and a fortiori evolutionary history, from the analysis of social forms, in favour of synchronic descriptions and a fundamentally typological approach to comparison (Tuzin 2001:2-3). Accordingly, anthropology overlooked 'one of society's most prominent features: incessant change in adaptive response to internal and external contingencies' (Tuzin 2001:4). He adds that it is only when we see this, and take it into analytical account, that we can understand 'social dynamics in the here and now' as well as how 'historical circumstances selectively affect social systems' (Tuzin 2001).

On Tuzin's account, the search for ways to understand social transformations was (luckily) carried on by archaeology, but its models tended to be unconvincingly materialistic and/or typological. One might have expected ethnographers to offer suggestions that would overcome these problems, but, because of anthropology's own history, few practitioners are ready to think about the functional relationship between how population size and societal complexity articulate with 'questions of causality, cognition, agency, and intentionality' (Tuzin 2001:6) to produce historical change significant on a societal scale: evolutionary change. Tuzin argues that material and typological models will remain inadequate as long as they are uninformed by more subtle understandings of the processes through which ideological and social factors are integrated with the material, in mechanisms driving changes in social morphology. Such changes, whether they occur in a 'forward, backward or sideways' direction, always occur in a concrete 'adaptational matrix bounded by space, time and population' (Tuzin 2001:9). He draws a parallel here with organic evolutionary theory, which became convincing only once Darwin provided a framework ('descent with modification by natural selection') that directed attention to the dynamic mechanisms of change (Tuzin 2001:7). Real social evolutionary inquiry seeks to understand 'processes of change and the emergence of novelty within sociocultural systems' (Tuzin 2001:8). 
Tuzin's analysis of 'the evolving society of Ilahita village and the external events and internal mechanisms implicated in its increasing size and complexity' (2001:10) aims to underscore the poverty of typological approaches that lack models of the dynamic mechanisms involved. It sought to show: a) the adaptive nature of organisational complexity based on ritual institutions structured by dualistic principles; while also elucidating b) 'the rather severe limits to settlement growth and organizational complexity facing societies of Ilahita's type' (Tuzin 2001:10). If he speaks of 'types' here - the very term he has worried about earlier - it is because he believes his study will indicate general patterns in 'the movement of simpler, small-scale societies to more complex, largescale societies' (Tuzin 2001:124). To that extent, analysis of societal dynamics generates its own, causally relevant types (Tuzin 2001:9), while making room for 'unique communal biograph[ies]' (p. 124).

The book once more tells (with some significant differences in emphasis) how nineteenth-century population changes connected with warfare and migration posed an urgent question to the traditional socio-cultural forms in one part of the Sepik region shared by Arapesh, Kwanga and Abelam populations. Ilahita's Arapesh population suddenly faced an influx of refugees from these other groups. The answer to the question could not come from Ilahita's 'subsistence base or technology' (Tuzin 2001:17), but was found in the elaboration of a new form of the regional 'cult of war and human sacrifice', produced by the iteration of dualistic ritual categories and resulting in 'the most complex system of its type ever documented', with eight crosscutting dual categories (and, therefore, 256 distinct ritual-categorical identities). He stresses, though, that '[f]rom top to bottom, the dual organisation is cast in ritual terms'; furthermore, because it also embraces kin relations, economic activities (production for exchange and for consumption) and political competition and conflict (between descent and residential groupings), even the most 'practical' actions are seen by Ilahitans to be mandated by the Tambaran cult and 'suffused with spiritual meaning' (Tuzin 2001:83).

Tuzin emphatically concluded (in rather Weberian tones) that the Tambaran cult in Ilahita amounted to 'the emergence of a rationalised religious ethic - a body of doctrine against which behaviour could be compared, evaluated, and, if necessary, punished...[and], moreover, which summarized and transcended the level of individual clan spirits' (2001:103, emphasis in original). It featured a unique, 'transcendent' spiritual patron for the village as a whole, one that 'allied itself with the elders of the cult' (Tuzin 2001:103). These elders - men spread across the village's components - were (also uniquely, in the cults of the region) united by a special grade and charged with making the most of the politically significant interventions, which they made in their own and the village's interests and with the full moral weight of the Tambaran, whose power 
was at their disposal. But the cult and its divisions also provided an arena for the competition and conflict generated by the rather pervasive intra-village strife, so that even social discord acted to enfold the binding, dualistic structure into the quotidian emotions of residents. In turn, the dual structures and the ritual prescriptions they embodied were reinforced by the interpersonal and intergroup antagonism that life in this large village engendered (Tuzin 2001:119-20).

Let us now consider some of the new orientations in Social Complexity in the Making. In Tuzin's earlier work, the spirit if not the letter of structuralfunctionalist conceptions of 'system' were patent; his bifurcated view of the process leading up to Ilahita's increase in size and complexity (described earlier) - with a social system having an internal dynamic that tends to homeostasis moving through an historical ambience that can usually (but not always) be counted upon to remain stable - evokes much of late structuralfunctionalist thought, which had still not entirely relinquished its attachment to the organismic analogy. Tuzin stressed both 'the equilibrium, preservation and development' of the 'organic-like' social systems and their susceptibility to being sustained or transformed by individuals' actions, even while these are themselves 'conditioned' by cultural understandings (which tend to be shared, of course). In the later works, though, the conditioning and the effects of individual actions implicate circumstances broader than those specific to the social system, which nevertheless tends to remain the unintended-and perhaps rather fragile - outcome of decisions and actions taken by individuals. The actors focus on the Tambaran and 'miss' the systemic connections that its power in their lives presupposed; 'the [actors] look after the details and the system looks after itself' (Tuzin 2001:83), but the process is 'non-teleological'. The 'logic of the situation' of the actors, given the circumstances and other factors 'accidental to the structure of the overall system', suffices to bring about the evolutionary transformation of Ilahita; but it was 'an emergent property of experience: the actions, perceptions, and ideas of individuals in a collective, temporal setting' (Tuzin 2001:84).

By 2001, then, society's tendency to 'incessant change' is stressed (Tuzin 2001:4), although Tuzin still cites Radcliffe-Brown on the evolution of systems as though the process were endogenously driven, and still sometimes evokes 1960s theoretical divisions. ${ }^{2}$ Yet, he also writes of the need to appreciate the role of 'the mechanisms at work in the adaptational matrix bounded by space, time and population; for it is only through those mechanisms that societies move' (Tuzin 2001:9, emphasis added). And while, in the next paragraph, he will

2 Thus, for example, 'while the dual organization gives the Tambaran structural coherence and social effectiveness, the Tambaran infuses the dual organization with cultural meaning' (Tuzin 2001:14), which, for me, very strongly calls to mind the function/meaning duality that thematised the notion of a cultural system for Geertz during the 1960s. 
again use terms that suggest a dichotomy between internal social mechanisms and external processes, the particularities of historical processes themselves, which are as responsible for the reproduction of social systems as for their transformation, and which are 'always already' open (and can be closed only as an analytical strategy), are more securely established as the focus of his concern with how cultural systems change. Tuzin, it seems to me, is by 2001 fairly clearly thinking about social life and change in terms of contingent, open systems, the elements of which are in interaction with one another; local cultural traditions, human psychological capacities and the broader environment of the concrete population (broadly construed, to include the socio-political as well as the physical ecology) are all aspects of the systematicity, or otherwise, of social life. ${ }^{3}$

I do not want to be dogmatic about the depth or extent of the transformation in Tuzin's views, but I do think he defined more precisely what an anthropology grounded in the 'cultural, psychological and biological wholeness' of human behaviour would involve. And this happened, I think, as he discussed with himself and his colleagues (and, at UCSD, he was well located for such discussions; see Lipset and Roscoe, this volume) the articulation of cultural, sociological and psychological perspectives in accounting for specific ways of life. He also came to appreciate how the works of such psychologists as Nicholas Humphrey and Elisabeth Spelke, and those of such adventurous, synthesising anthropologists as Dan Sperber and Pascal Boyer, related to his own (Tuzin 2002).

In 1984, Tuzin had already had to defend himself against some rather crude charges that his argument about the role of the experience of certain auditory properties in religious practices was 'reductionist', and he had accepted and elaborated upon Michael Young's suggestion, in the latter's commentary on that essay, that it sought to argue from 'culture to nature to brain/mind and back again' (Young 1984:594). By 2002, Tuzin was happy to risk 'anti-reductionist rage' (2002:10) in considering the cognitive basis of intuitive expectations relevant to the experience of art in ritually prepotent contexts. I have nothing but his texts to go on, but I think that when, through the late 1980s and 1990s, his pursuit of his interactionalist paradigm led him into the burgeoning literatures in developmental psychology and cognitive science, he came to reconceptualise not just how the cultural, psychological and biological were interrelated but how each realm was itself constituted. It seems that he came to share the sense of incredulity at mainstream anthropology's lack of interest in widely dispersed or universal psychological characteristics that, for example, Sperber had expressed in many forms, and which Boyer addressed at length in relation to religion in his 1994 work (published, perhaps significantly, by University of California Press).

3 Although I will not deal with his account of the demise of the Tambaran cult (Tuzin 1997) and the fracturing of Ilahita's unity, I think these events, which were contingent on the effects of colonial forces within Ilahita's social fields, acted to confirm Tuzin in his perspective. 
Perhaps he was also persuaded to consider these theorists' epidemiological, processual perspectives on culture, which tend to undermine the very notion of social life as a systems-theoretic phenomenon. While, I admit, this line is somewhat speculative, Social Complexity in the Making presents formulations of Ilahita's past that contrast with his earlier accounts, and it does so in ways that suggest that Tuzin had been influenced by models of social process that involve selection on populations of variants over time. While this is not fundamentally at odds with his earlier perspectives, the analytical space that he had previously assigned to social systems at equilibrium, and to structural explanation, would seem to have diminished. Nevertheless, the continuities over the 25-year span are very striking. He still, for example, conspicuously invokes Popper and his non-Hobbesian individualism, so I now broaden the discussion in an effort to show that Tuzin's analytical commitments are not best supported by such invocations.

\section{Individuals, Individualism and Processes}

In this section, I will try to detach Tuzin's interactionalist practice from his avowed attachment to Popperian MI. I will briefly discuss Popper's views and those of his most influential followers, such as Watkins and Agassi, mostly to suggest that these never amounted to a coherent position. I will then suggest, even more briefly, that Tuzin's analytical ambitions could fruitfully be compared with those of Max Weber, as could, perhaps, the spirit of his defence of MI and Weber's views on the matter. Finally, I will say something about more recent attempts to set the relations between ontological and methodological considerations on a more precise footing, which, for many scholars, have resulted in a more reasonable picture of the import of the distinction between holists and individualists.

\section{Popper's Agenda and Tuzin's Analysis}

Recall that for Tuzin the relationship between culture, society and the individual constitutes the central problem for anthropology; on the face of it, this statement implies the existence of all three sorts of entity whose relationship is at issue. What in facing the matter of their integration led Tuzin to align himself with the views of Popper, Watkins and Agassi? First, unlike other approaches that proclaim their methodological individualism, Popper's MI usually insisted on the autonomy and facticity of the social (institutions, norms, and so on) no less than the agency of subjects. Popper applauded Marx for having shown, against John Stuart Mill, that the social sciences must be autonomous of the psychological sciences, since the actions of individuals could not be explained 
without reference to institutions (Popper 2003:100), which 'set limits or create obstacles to our movements and actions almost as if they were physical bodies or obstacles'; indeed, they 'are experienced by us as almost literally forming part of the furniture of our habitat' (Popper 1994:167). Tuzin emphasises Popper's rejection of atomistic individualism of the sort associated with Hobbes and repeatedly endorses the connected Popperian view about the crucial role of the unintended consequences of actions in human social history. Popper came to stress more and more the role of institutions and the responsiveness of individuals to the 'logic' of their situation, to the point where he gave up the term 'methodological individualism' (Udehn 2001:206). In their attempts to defend the position, Watkins, Agassi and Jarvie responded in contrasting ways, bringing out some of the ambiguities of Popper's original formulations (Udehn 2001:211-24).

It is hard, I think, not to have some sympathy for those who felt bewildered by the divisions that Popper's intervention in social-science methodology precipitated. What the debates (and their cross-purposes) indicate is the instability of the positions the protagonists adopted. Ruben states bluntly that 'methodological individualism has never been stated with enough clarity and precision to permit its proper evaluation' (1985:132). In its Popperian version, MI presented reasonable arguments against those who postulated a telos to local or universal history; and while insisting that human agency (purposes, decisions, theories, intentions, and so on) was an irreducible element of social life and its trajectories, and therefore of the history of the physical world as well, it affirmed the facticity of institutions. This mixture of the repudiation of (pre)deterministic doctrines, an insistence on human freedom and the openness of historical outcomes (with their unavoidable but causally relevant unintended consequences) proved unstable. Popperian MI was historically significant just because it addressed major questions in the philosophy of science while simultaneously opposing anti-humanist conceptions of society and history. With hindsight, it is apparent that the deductive models of explanation (in either covering law or falsificationist form) prevalent at the time restricted ideas about causal relations and their role in social life. In addition, the association of such models with inter-theoretical reduction in science made it rather obvious that the unwillingness of Popper and his followers to contemplate reduction of human cognitive powers to non-cognitive processes - given their insistence that social events (for all the facticity of their outcomes) be reduced to the actions of their human participants - was motivated by humanist politics rather than methodological considerations. Of course, the instabilities of MI were no less apparent in the holist positions that opposed and complemented it (many of which were also inspired by humanist political sensibilities), which is perhaps why today there are prominent MI defenders of Marx and thriving antiindividualist currents in mainstream economics. 
In concluding this cursory examination of Popperian MI and its tribulations, it is worth stressing that Tuzin's interest in this orientation stemmed from its empirical focus and its presumed capacity to explain both the reproduction of and the change in cultural forms, by providing an account of the social dynamics at any given time. Under all circumstances, social trajectories are inflected-but not set-by the decisions and actions taken by individuals in the face of the circumstances they confront.

\section{Tuzin and Weber on Culture and History}

This perspective was probably inspired by Tuzin's reading of Popper and Watkins, but it also seems close to the following: 'in sociological work... collectivities must be treated as solely the resultants and modes of organization of the particular acts of individual persons' (Weber 1978:13). Weber, though, will go on to warn that it is 'a tremendous misunderstanding' to think that a methodological focus on individuals has anything to do with individualistic political values, just as it is to think that a methodological interest in agents' reasons for acting indicates a 'belief in the predominance of rational motives, or even a positive valuation of rationalism' (1978:18). Weber's and Tuzin's views imply a demand for transparency in social explanation, and we have this only when we can relate social phenomena to how they are understood by the agents partaking of social phenomena. To take an utterly mundane example, what explains the shopkeeper's willingness to accept the pieces of paper I give her for a basket of good food is only elliptically explained when we refer to the laws or traditions of the place. What really explains what she does is her observance of the rules or traditions, or her concern about the law; the demand, then, is for the social facts and the 'subjective meanings' of individuals, for only then is the explanation complete (even though it is only rarely necessary to mention the obvious like this). Again, even if a decision or action is intimately tied to the individual's position - as a king, say - and motivated by the incumbent's knowledge of the cultural expectations attaching to it, it remains the individual's action, no less than when the king effects some historical coup only through a bold move that strategically violates those expectations.

The rationale for Weber's methodological focus on the individual is emphatically not, then, the political or ethical status of the human being, but the fact that it is the individual who takes action, and who is, therefore, the locus of an element that constitutes a central explanatory factor in many (but not all) of the circumstances of interest to the social scientist or historian. Weber's (1978:4) definition of sociology is predicated on this view. Action (that is, behaviour that is 'subjectively meaningful' to the agent), including, of course, interaction, is what makes for differences in the flow of social life, in cases when change is the historical outcome and when it is not. If we want causal understanding 
of the course of social life, and thereby the capacity to explain particular and general aspects of it, looking to people's actions is indispensable, Weber argues, no matter how routine the cultural context is for the agents. To the extent that it is action that is causally important, then it is somewhat misleading to think of Weber's methodology as stressing the individual rather than the collectivity, as Heath (2008) also points out (see also Ringer 1997:Ch. 4, 2002).

Two further points should be made here (even if they cannot be fully defended): first, the interpretation of subjective states relevant to action does not amount to a special kind of understanding, although it is a special kind of causal understanding; for Weber, we might say, there is no gap between identifying why somebody acted as she did, the subjective meaning the action had, and what action she performed. Second, the central role that Popper (and other methodological individualists, in economics as well as other social sciences) assigns to institutions ('rules of the road, police regulations, traffic signals... language, markets, prices, contracts and courts of justice' [Popper 1994:1667]) is also a crucial dimension of this Weberian scheme, where they feature as an aspect of the action itself (defined relative to its subjective meaning, as when I obey the traffic rules in stopping at the red light - or break them in an act of defiance) or an aspect of the outcomes the action causes (the anger of other motorists or the fine that results when I do not obey the lights) or, more usually, both. Together, these two points suffice to indicate something I shall return to below - that the Weberian picture set out so far does not amount to a psychological individualism of the sort Mill held (and Homans endorsed [1982:287]), which asserts that the

laws of the phenomena of society are, and can be, nothing but the laws of the actions and passions of human beings united together in the social state. Men, however, in a state of society, are still men; their actions and passions are obedient to the laws of individual human nature. Men are not, when brought together, converted into another kind of substance, with different properties; as hydrogen and oxygen are different from water. (Mill 1882:608)

For Weber, in contrast, it is clear that the historical and cultural context of an action is central to its very identity and therefore to its causal significance (as well as to the sorts of 'human nature' one will encounter in agents). If one were inclined, one could here invoke Geertz's (1973) account (by his own testimony, Weberian) of how our minds' properties (our 'moods and motivations' as well as our conceptions of the 'general order of existence') radically depend upon the historical state of the 'web of cultural meanings' we inherit, but it will be safer, given Geertz's mercurial shifts in perspective, to stick to Weber's original accounts. The point is merely to stress that there is nothing in Weber that 
suggests that what we need in understanding the subjective states relevant to socially significant actions should be looked for in the theories and findings of (sub-personal) psychology.

The reason for this (and for the complexity of Weber's analytical schemes, even taking account of his use of ideal types) is that action is constituted by the subjective meanings of the agent and these are highly conditioned by particular circumstances, so that social outcomes typically depend upon the minutiae of the setting. Sub-personal psychological and even biochemical factors are sometimes causally relevant to the development of the subjective meaning that constitutes an action, but the action itself has to be interpreted-indeed, defined - in relation to that meaning. On the other hand, there is nothing at all in Weber to encourage those who wish to see the return to centre stage of the inscrutable 'voluntarist' individual, the uncaused cause of micro and macrosocial trajectories (the 'intolerably spoilt child' that the social sciences worked so hard to displace [Lévi-Strauss 1981:687]). The meanings in terms of which the subject acts, and therefore the actions taken that inflect to a greater or lesser extent the course of social(-historical) events, are themselves contingent on the social biographical circumstances (which, of course, implicate the institutions and social currents of the milieu).

Many of Tuzin's explicit statements about MI could be read as echoing portions of Weber's methodological writings, but a more telling convergence of perspective, as I have already claimed, is revealed by the profile of ethnographic studies Tuzin produced - in particular, the variety of factors he held to be relevant to the explanation of the growth of Ilahita, the maintenance of its social form and then its demise. Of particular significance is his insistence that we should focus on individuals, their particularities and their actions because of their causal significance for socio-historical processes as factors involved in the interaction between the historical traditions of Ilahita culture, the population and its environment (construed in the broadest terms). It seems, then, that for Tuzin (especially in his later work), as for Weber, societies are best conceived as processes. Less speculatively, for Tuzin, as for Weber, while society and its cultural forms are unintentionally produced and reproduced by acting individuals, their actions are irreducibly dependent upon the culture into which they are born. Cultural context, the individual meanings to which these are causally relevant (and which are partly constitutive of action) and the unintended consequences of agents' activities are equally indispensable to the social and historical disciplines. 


\section{Holist Individualism}

If, as I have suggested, Weber could have provided Tuzin with better support for his interactionalist perspective than the brand of MI he drew upon, it remains to answer someone who might be preoccupied with the idea that, nevertheless, Popper provided the sort of philosophical or meta-theoretical perspective that Tuzin sought in opposing prevailing structuralist paradigms. Well, I think this worry can be addressed.

The debates about methodological individualism that took place through the 1950s and 1960s were deeply affected by the program of inter-theoretic reduction intimately associated with the deductive model of explanation, a paradigm of which was the reductive deduction of the gas laws from the kinetic theory. The difficulties of that program (which stemmed not only from the failure of attempts to generalise the paradigm just mentioned, but also from, for example, the complex and clearly non-deductive relations between domains within biology [Bechtel and Hamilton 2007]) also played an important part in changing the focus of debates about MI and, connectedly, in the development of a novel construal of the ontology of social life and its methodological implications. For, while awareness of the difficulties of the deductive picture of inter-theoretic reduction spread (along with broader concerns about empiricist and positivist models), it was nevertheless hard to abandon the conviction that there was indeed a fundamental relationship between mean kinetic energy of molecules and temperature, between the molecular gene and the gene of population genetics or, most notably (given the advent of cognitive science), the mind and the brain. These and other factors ensured that the search for micro-foundations for biological and cognitive phenomena remained important (Bechtel and Hamilton 2007; Bickle 2008; Oddie 2001). Accordingly, other, more subtle notions of the dependency between domains were explored and developed.

Discussions of such 'supervenience' relations and cognate notions pertaining to the metaphysics of identity have galvanised the philosophy of mind and the cognitive sciences since the 1970s (although it has also been important in ethics, aesthetics and the philosophy of science). The term 'supervenience' applies to the relations between properties in two domains, S and B, and is usually expressed by a slogan along the lines of 'changes in S-properties only if there are changes in B-properties'. So, properties relevant to one domain (the mental, say) supervene upon those of another (the neurophysiological, say) when the former can undergo no change that is not a change in the latter ('base' or 'subvening') 
domain. Thus, there can be no change of mental properties without a change of neurophysiological properties; it is important to note, however, that changes in base properties do not entail changes in the supervening ones. ${ }^{4}$

The impact of this notion stemmed from its introduction in the philosophy of mind, where it seemed to offer the possibility of a non-reductive account of the relations between the mental and the physical, while also defining an ecumenical space wherein the various particular disciplines ('the special sciences') could retain their autonomy. Moreover, each could do so without having to commit to any process or principle that might bring it into conflict with the fundamentals of the picture painted by physics. Accordingly, it was not long before scholars began thinking about the relations between the realms of the individual (or some more precise notion) and the socio-cultural in terms of supervenience, for it seemed to hold out 'the promise of prizing apart the methodological and ontological issues, enabling, for example, both the metaphysical strictures of the [ontological] individualist and the methodological dispositions of the holist to be accommodated' (Oddie 2001:12858). This was undoubtedly a liberating departure, for it facilitates a realisation that seeing individuals and social entities on a model of parts and wholes is metaphysically inadequate. Supervenience is, however, a modal notion; it says what is necessary and, therefore, what is possible (for the two terms are inter-definable); this means that it is susceptible to treatment within the technical apparatus of contemporary modal logic. Complexity is also guaranteed by the fact that different kinds of necessity/ possibility can be at stake: 'necessity abounds', Fine observes (2005:235), in logic, mathematics, metaphysics and nature, and it is no easy matter to sort and classify 'this abundance'. A recent authoritative overview, for example, lists six categories of supervenience, each divided into two or four subcategories (McLaughlin and Bennett 2008). Rather than even think about introducing further discussion of supervenience, I will quickly describe one influential attempt to deploy the basic idea in thinking through the issues that preoccupied the Popperians, as well as Don Tuzin: Philip Pettit's The Common Mind (1993).

In this ambitious synthetic work, Pettit links political orders to social orders and the latter to human psychological characteristics, at the core of which are our powers as intentional, thinking subjects. ${ }^{5}$ In place of the usual dichotomy between holism and individualism, Pettit considers the relations between

\footnotetext{
4 Equivalently, identity between two entities (objects, events, states) in their subvening properties entails their identity in supervening properties, but not vice versa.

5 On Pettit's view, developed in the first of the book's three sections, thinking subjects are a subset of intentional beings; an intentional being is one who has states (pre-eminently, wants or aims and 'beliefs' cognitive, truth-evaluable states) appropriately connected to its environment and whose characteristics explain its behaviours, while thinking beings also have the capacity to make their first-order intentional states the subject of desires and complex sets of beliefs. Briefly, if you and your pet dog believe the snake that just reared up before you is dangerous, you, as a thinking subject, will, in contrast with your dog, believe that it is true that the snake is dangerous (you will argue the toss with those inclined to doubt it), hold that there is
} 
the social and the psychological orders in terms of two distinctions: between individualism and collectivism and between atomism and holism. He argues that the conflation of these two distinctions has been encouraged by the mistaken idea that individual agents stand to the societies of which they are members as parts to wholes. He characterises the difference between the distinctions in terms of a spatial metaphor: individualists and collectivists differ on the significance of the vertical relations between regularities that obtain in domains of social life, while atomists and holists differ on the question of the horizontal relations between the essential features of agents and those of society:

Individualists deny and collectivists maintain that the status ascribed to individual agents in our intentional psychology is compromised by aggregate social regularities. Atomists deny and holists maintain that individual agents non-causally depend on their social relations with one another for some of their distinctive features. (Pettit 1993:118)

Pettit spends a chapter on each distinction, arguing against the collectivist in one and against the atomist in the other; not only is our intentional psychology not compromised by aggregate social regularities, it is also necessary for them, while our intentional psychology - our status as thinking subjects - is superveniently dependent' (1993:228) upon our being members of a linguistic community of socially interacting subjects. In sum, Pettit argues for holistic individualism, which preserves the insights of romantic and historicist philosophers, as well as major social-scientific theorists, while avoiding the postulation of ontologies that are hard to reconcile with those of other sciences. The separation of ontological and methodological issues central to the discussion of supervenience and associated notions offers metaphysical austerity and the plurality of autonomous sciences: biological, psychological and social phenomena are scaffolded by, but irreducible to, physically fundamental processes. As Pettit's work shows, this powerful vision is naturally extended to areas of social and political theory. And while important, connected questions about causal relations and the nature of explanation remain for the friends of supervenience (as they do for friends of other approaches), the program of nonreductive physicalism has certainly shown the confusions that attend the failure to distinguish between the supervenience of A properties on B properties, the reduction of $\mathrm{A}$ properties to $\mathrm{B}$, and the elimination of $\mathrm{A}$ properties in favour of B properties. It is reasonable to expect that if these distinctions became more widely available in the social sciences, some of the anxieties (and sloganeering) about determinism and reductionism might become things of the past.

evidence to that effect in the circumstances (which you are prepared to point out to your doubting friend), wish, perhaps, that it were false that the snake was dangerous, and so on. His argument that being a thinking subject involves non-causal dependencies on social relations is crucial to the remainder of the book. 
The sort of non-reductive individualism that Pettit sets out amounts to the replacement of the dualism between the social and the individual with a continuum between the macro-social through the meso-social to the micro-social, where we encounter particular persons. The most important implication is that persons are socio-historical beings, in fact and by metaphysical necessity. (To that extent, the continued use of an undifferentiated notion of the individual is to be avoided, for it too easily evokes those Hobbesian atoms that are projected as only contingently social beings.) So, on the arguments of Pettit and others (such as Currie 1984, 1988, 2001), persons are 'always already' social entities, for they are necessarily defined relationally. Pettit (1993:229) goes on to elaborate a view that he (and Frank Jackson) calls explanatory ecumenism, according to which 'intentional, structural, historicist and rational choice styles of explanation are complementary enterprises' (see also Jackson and Pettit 1992a, 1992b; Pettit 1998). Calling them 'styles of explanation' does not really do justice to Pettit's conception of the relationships involved in these different areas of endeavour. What matters is being precise about the question we wish to pose: are we asking about the decisions of this clan leader in that context, or about the context, or about the broad institutional setting that defined the context in that way, or about the history of that configuration of institutions?

What makes the sort of ecumenical, 'interactionalist' approach Tuzin favoured, and Pettit explicitly defends, so important is that it subverts the simple individual-society couple that has inflected debate since Durkheim. Pettit's analysis, however, and the considerations upon which he grounds it, also undermines Tuzin's stated MI grounds for his approach. It would be possibleand for many purposes, desirable - to pursue further the approach Pettit takes and the many questions and difficulties it raises. But given limitations of space, it seems more worthwhile to conclude by returning to my introductory rehearsal of social-science commonplaces.

\section{Concluding Remarks}

Those commonplaces indicate that a great many of the states any given person is in are defined socially and relationally; so description of a person already entails the sort of relations that MI is sometimes aimed at accounting for. Social properties are contingently acquired by an individual through the process of socialisation (which amounts to ontogenesis), but having a particular social property - such as being a citizen, taxpayer, or an enrolled school student, or in a particular Arapesh initiation class - is non-contingently dependent upon enjoying the right sort of relations with aspects of society (just as what it is for something to be legal tender is a matter of its relational history [Searle 2010]). Admittedly, a general account of the relations relevant to overall personhood is 
a difficult ontological question. But there are physical entities and states that are defined by their having the right sort of causal historical relations with prior events: footprints, skid marks, sunburn, shaving cuts and whiplash injuries are obvious examples; but being a tiger or an oak is a matter of causal history, while being a thermostat is less a matter of physical constitution than causal powers. While these examples are helpfully suggestive, the relations involved in someone's being a divine king, cult elder, citizen, mayor or judge, or for something to be a signature or a football field, are more complex still. In fact, the relations that matter seem to be between agents and appropriate states of mind (Currie 1988) - prior states of one's own mind (as my currently being under contract entails prior actions, and therefore intentions, of mine) and, more importantly, states of other minds, recursively linked together, as they are in linguistic communication. So not only are social states and processes relational, they apparently involve irreducibly mental states - states it is notoriously difficult to identify with any non-mental substrate (not least because they too are relational).

Interestingly, once we abandon hope of accounting for aspects of the social life of humans in terms that abstract from our status as intentional, social beings (which is akin to trying to account for the natural history of sharks in terms that abstract from the properties they have as predatory fish), it becomes difficult to specify a sense of individual that is not parasitic on the one we use pretheoretically. So social relations depend (supervene) on mental states, which, in turn, have dependencies on the conventions and practices of social life (in the sense that my worrying whether my dole cheque is on its way is a state of mind that entails the existence of certain socio-historical conditions).

All this is not to deny that there is - and necessarily so-some substrate that is the possessor of a social property; and it is hard to see how this could be anything other than a being with a sufficiently rich psychology (rich enough to permit language learning, for example), or something (such as the football field) defined as such by beings of that sort. While, though, there are obvious candidates for bearers of social properties (human beings), specifying them in ways that do justice to typical cases (mature cultural beings) without presupposing the socio-cultural is a forlorn hope, as the difficulties of MI indicate. This, in turn, means that it makes little sense to think of concrete individuals as basic parts of social wholes (Currie 1984, 1988; Pettit 1993, 1998; Ruben 1985). And if one thinks carefully about the relations among armies, soldiers and the people who signed up, or between the team, the club it represents and the players, or between the clan, its subclans and the current members, one can appreciate that we are dealing with something other than simple aggregates - like those who are waiting right now at the local bus stop. If I am one of the group waiting at a particular bus stop, and that group is one of the many making up the larger 
group of people waiting for buses on the high street, I am a member of the larger group, whereas (as Ruben shows), if you are an Australian citizen, and Australia is a member of the United Nations, it does not follow that you are a member of the United Nations. And whereas the group of people sitting in the café or residing in an Ilahita ward changes as persons come or go, neither the library committee nor the Afinga clan is transformed when one member is replaced with another (even if this has effects on other interpersonal relations, the tenor of meetings or the chances of internal disputes, and so on).

Coping with the complexities of the relations between social entities is, then, a metaphysically challenging task, and that makes formulating explanations capturing causal relations among them less than straightforward. This state of affairs need not worry us, however; we might still think (as Weber did, and historians usually do) that there is still much analytical satisfaction to be had from showing how, for example, economic depressions, wars or the rise of new social classes causally relate to the actions and decisions of individuals and identifiable social collectivities, picked out in the usual intuitive terms; or from appreciating how certain religious doctrines, which might demand a great deal of interpretation on our part, grew and spread through one stratum of society, but not others. It was only in this (folk psychological) sense that Weber was an individualist; he seems to have crafted his sociology to be ontologically and methodologically continuous with history and with our folk psychology. And these resources might be all that we need to understand how Ilahita, under pressure from expanding populations around them, made accommodations that involved, among other things, the elaboration of existing practices and their deployment in the novel historical circumstances, and that what eventuated was something unprecedented in the area. Of course, we will have lots of questions about those practices, their histories, their connections with one another, and with human psychology; and when it comes to some very particular aspects of events (why the turn to Christianity at that juncture [Tuzin 1997]), we might want to know about the personal characteristics of individuals (such as Samuel). Usually, however, the characteristics of typical individuals with locally specific, shared understandings set in the broader contexts of their human condition will suffice.

Finally, where does this perspective leave Don Tuzin's interactionalist paradigm and his hopes for an anthropology 'both humane and humanistic...of great moral and scientific importance'? I think it leaves it in as good a shape as he might have wished for when he began his stunning exposition of Ilahita's fortunes in the 1970s. Indeed, I would argue that it leaves his version of interactionalism in a somewhat stronger position than that of prominent others who share Don's interactionalist ambitions, such as Sperber and Boyer. Don could help himself to what we might call 'the anti anti-reductionist' case that these scholars have 
made so strongly over the years (see, for example, Sperber 1996) and to the openness to integration with evolutionary history that this naturally provides. Yet, the sensitivity of Don's approach to those particular historical features that Sperber's model of culture packages together as 'ecological factors' makes it more apt than Sperber's for the single-case historical-ethnographic study. And just such studies are the ones prized by those who want anthropologists to continue to produce cultural accounts thick enough to warrant Rorty's description of us as 'agents of love' (1986), or who think the discipline should remain dedicated to addressing what Geertz insisted on calling our 'moral imagination' (1983). What makes Tuzin's work so outstanding is that it can appeal no less convincingly to both perspectives, even while they see themselves as opposed. ${ }^{6}$

\section{References}

Bechtel, William and Andre Hamilton 2007. Reduction, Integration, and the Unity of Science: Natural, Behavioral, and Social Sciences and the Humanities. In Theo A. F. Kuipers (ed.) Philosophy of Science: Focal Issues, pp. 377-430. New York: Elsevier.

Bickle, John 2008. Multiple Realizability. In Edward N. Zalta (ed.) The Stanford Encyclopedia of Philosophy, Stanford, Calif.: Stanford University, <http:// plato.stanford.edu/archives/fall2008/entries/multiple-realizability/>

Boyer, Pascal 1994. The Naturalness of Religious Ideas. Berkeley and Los Angeles: University of California Press.

Currie, Gregory 1984. Individualism and Global Supervenience. British Journal for the Philosophy of Science 35:345-58.

Currie, Gregory 1988. Realism in the Social Sciences: Social Kinds and Social Laws. In Robert Nola (ed.) Relativism and Realism in Science, pp. 205-27. Amsterdam: Kluwer Academic.

Currie, Gregory 2001. Methodological Individualism. In Neil J. Smelser and Paul B. Bates (eds) International Encyclopedia of the Social and Behavioral Sciences, pp. 9755-60. Amsterdam: Elsevier Science.

Durkheim, Emile 1973. The Dualism of Human Nature and its Social Conditions. In Robert N. Bellah (ed.) Emile Durkheim on Morality and Society, pp. 14964. Chicago: University of Chicago Press.

\footnotetext{
6 These closing - admittedly rhetorical - remarks are a little unfair to Sperber's views, which need to be seen as but a small part of a broader and extremely interesting vision that cannot even be sketched here.
} 
6. Comparison, Individualism and 'Interactionalism' in the Work of Donald F. Tuzin

Fine, Kit 2005. Modality and Tense: Philosophical Papers. Oxford: Oxford University Press.

Freeman, Derek 1966. Social Anthropology and the Scientific Study of Human Behaviour. Man (NS)1:330-42.

Freeman, Derek 1983. Margaret Mead and Samoa: The Making and Unmaking of An Anthropological Myth. Cambridge, Mass.: Harvard University Press.

Geertz, Clifford 1957. Ritual and Social Change: A Javanese Example. American Anthropologist 59:32-54.

Geertz, Clifford 1973. The Interpretation of Cultures. New York: Basic Books.

Geertz, Clifford 1983 [1977]. Found in Translation: On the Social History of the Moral Imagination. In Local Knowledge: Further Essays in Interpretive Anthropology, pp. 36-54. New York: Basic Books.

Heath, J. 2008. Methodological Individualism. In Edward N. Zalta (ed.) The Stanford Encyclopedia of Philosophy, Stanford, Calif.: Stanford University, $<$ http://plato.stanford.edu/archives/fall2008/entries/methodologicalindividualism/>

Hedström, Peter, Richard Swedberg and Lars Udehn 1998. Popper's Situational Analysis and Contemporary Sociology. Philosophy of the Social Sciences 28:339-64.

Homans, George C. 1982. The Present State of Sociological Theory. Sociological Quarterly 23:285-99.

Infantino, Lorenzo 1998. Individualism in Modern Thought: From Adam Smith to Hayek. New York: Routledge.

Jackson, Frank and Philip Pettit 1992a. Structural Explanation in Social Theory. In David Charles and Kathleen Lennon (eds) Reduction, Explanation, and Realism, pp. 97-131. Oxford: Clarendon Press.

Jackson, Frank and Philip Pettit 1992b. In Defence of Explanatory Ecumenism. Economics and Philosophy 8:1-21.

Kottak, Conrad P. 2008. Mirror for Humanity: A Concise Introduction to Cultural Anthropology. New York: McGraw-Hill.

La Barre, Weston 1980. Culture in Context: Selected Writings of Weston Labarre. Durham, NC: Duke University Press.

Lévi-Strauss, C. 1981. The Naked Man. J. \& D. Weightman (trans). Introduction to a Science of Mythology. Volume 4. New York: Harper \& Row. 
McLaughlin, Brian and Karen Bennett 2008. Supervenience. In Edward N. Zalta (ed.) The Stanford Encyclopedia of Philosophy, Stanford, Calif.: Stanford University, <http:/plato.stanford.edu/archives/fall2008/entries/ supervenience/>

Marx, Karl 1963 [1869]. The Eighteenth Brumaire of Louis Bonaparte. New York: International Publishers.

Mill, John Stuart 1882. A System of Logic, Ratiocinative and Inductive. [Eighth edition.] New York: Harper \& Brothers.

Moore, Wilbert E. 1979. Functionalism. In T. B. Bottomore and Robert A. Nisbet (eds) A History of Sociological Analysis, pp. 321-61. London: Heinemann Educational.

Oakley, Allen 2002. Popper's Ontology of Situated Human Action. Philosophy of the Social Sciences 32:455-86.

Oddie, Graham 2001. Reduction: Varieties of. In Neil J. Smelser and Paul B. Bates (eds) International Encyclopedia of the Social and Behavioral Sciences, pp. 12 857-63. Amsterdam: Elsevier Science.

Pettit, Philip 1993. The Common Mind: An Essay on Psychology, Society, and Politics. Oxford: Oxford University Press.

Pettit, Philip 1998. Defining and Defending Social Holism. Philosophical Explorations 1:169-84.

Popper, Karl R. 1994. The Myth of the Framework: In Defence of Science and Rationality. M. A. Notturno (ed.). London: Routledge.

Popper, Karl R. 2003 [1945]. The Open Society and Its Enemies: Hegel and Marx. Volume 2. Oxford and New York: Routledge.

Ringer, Fritz K. 1997. Max Weber's Methodology: The Unification of the Cultural and the Social Sciences. Cambridge, Mass.: Harvard University Press.

Ringer, Fritz K. 2002. Max Weber on Causal Analysis, Interpretation, and Comparison. History and Theory 41:163-78.

Rorty, Richard 1986. On Ethnocentrism: A Reply to Clifford Geertz. Michigan Quarterly Review 25:525-34.

Ruben, David-Hillel 1985. The Metaphysics of the Social World. London: Routledge and Kegan Paul.

Searle, John R. 1995. The Construction of Social Reality. New York: The Free Press. 
6. Comparison, Individualism and 'Interactionalism' in the Work of Donald F. Tuzin

Searle, John R. 2010. Making the Social World: The Structure of Human Civilization. Oxford and New York: Oxford University Press.

Schütz, Alfred 1973. The Phenomenology of the Social World. George Walsh and Frederick Lehnert (trans). Evanston, Ill.: Northwestern University Press.

Sperber, Dan 1996. Explaining Culture: A Naturalistic Approach. Oxford: Blackwell.

Spiro, Melford 1978. Culture and Human Nature. In George D. Spindler (ed.) The Making of Psychological Anthropology, pp. 331-60. Berkeley: University of California Press.

Turner, Stephen P. and Regis A. Factor 1994. Max Weber: The Lawyer as Social Thinker. London: Routledge.

Tuzin, Donald F. 1974. Social Control and the Tambaran in the Sepik. In A. L. Epstein (ed.) Contention and Dispute: Aspects of Law and Social Control in Melanesia, pp. 317-44. Canberra: Australian National University Press.

Tuzin, Donald F. 1976. The Ilahita Arapesh: Dimensions of Unity. Berkeley: University of California Press.

Tuzin, Donald F. 1980. The Voice of the Tambaran: Truth and Illusion in Ilahita Arapesh Religion. Berkeley: University of California Press.

Tuzin, Donald F. 1982. Ritual Violence Among the Ilahita Arapesh: The Dynamics of Moral and Religious Uncertainty. In Gilbert H. Herdt (ed.) Rituals of Manhood: Male Initiation in Papua New Guinea, pp. 321-55. Berkeley: University of California Press.

Tuzin, Donald F. 1984. Miraculous Voices: The Auditory Experience of Numinous Objects. Current Anthropology 25:579-96.

Tuzin, Donald F. 1989. Visions, Prophecies, and the Rise of Christian Consciousness. In Gilbert Herdt and Michelle Stephen (eds) The Religious Imagination in New Guinea, pp. 187-210. New Brunswick, NJ: Rutgers University Press.

Tuzin, Donald F. 1991. The Cryptic Brotherhood of Big Men and Great Men in Ilahita. In Maurice Godelier and Marilyn Strathern (eds) Big Men and Great Men: Personifications of Power in Melanesia, pp. 115-29. Cambridge: Cambridge University Press.

Tuzin, Donald F. 1997. The Cassowary's Revenge: The Life and Death of Masculinity in a New Guinea Society. Chicago: University of Chicago Press. 
Echoes of the Tambaran

Tuzin, Donald F. 2001. Social Complexity in the Making: A Case Study Among the Arapesh of New Guinea. London: Routledge.

Tuzin, Donald F. 2002. Art, Ritual, and the Crafting of Illusion. Asia Pacific Journal of Anthropology 3:1-23.

Tuzin, Donald F. 2006. Base Notes: Odor, Breath and Moral Contagion in Ilahita. In Jim Drobnik (ed.) The Smell Culture Reader, pp. 59-67. New York: Berg.

Udehn, Lars 2001. Methodological Individualism: Background, History and Meaning. London: Routledge.

Udehn, Lars 2002. The Changing Face of Methodological Individualism. Annual Review of Sociology 28:479-507.

Watkins, J. W. N. 1955. Methodological Individualism: A Reply. Philosophy of Science 22:58-62.

Watkins, J. W. N. 1957. Historical Explanation in the Social Sciences. The British Journal for the Philosophy of Science 8(30):104-17.

Weber, Max 1952. Ancient Judaism. Hans H. Gerth and Don Martindale (eds and trans). London: Allen \& Unwin.

Weber, Max 1978. Economy and Society: An Outline of Interpretive Sociology. Guenther Roth and Claus Wittich (eds). Berkeley: University of California Press.

Young, Michael W. 1984. Response to Miraculous Voices: The Auditory Experience of Numinous Objects. Current Anthropology 25:593. 